\title{
ESTRESSE E LESÕES EM ATLETAS DE ESPORTES COLETIVOS
}

\author{
Marcos Vinícius Sichieri Akamine ${ }^{1}$ \\ Patricia Carolina Borsato Passos ${ }^{2}$ \\ Gislaine Contessoto Pizzo ${ }^{3}$ \\ Luciane Cristina Arantes da Costa ${ }^{4}$
}

\begin{abstract}
AKAMINE, M. V. S.; PASSOS, P. C. B.; PIZZO, G. C.; COSTA, L. C. A. da. Estresse e lesões em atletas de esportes coletivos. Arq. Cienc. Saúde UNIPAR, Umuarama, v. 20, n. 1, p, 25-31, jan./abr. 2016.

RESUMO: O objetivo deste estudo foi analisar os níveis de estresse em atletas lesionados de modalidades coletivas de um município do noroeste do Paraná. Os sujeitos da pesquisa foram 14 atletas de ambos os sexos, com média de idade 23,5 anos. Como instrumentos foram utilizados o Restq - Sport 76 e entrevista semiestruturada. Para análise dos dados, utilizaram-se o teste Shapiro Wilk e "U" de Mann-Whitney $(\mathrm{p}<0,05)$; na análise das questões abertas foi realizada a análise de conteúdo. Os resultados demonstraram que as ocorrências de lesões foram maiores em atletas de rugby e a localização das lesões, nas modalidades em geral, foram mais frequentes nos joelhos e ombros. Em relação ao estresse foram encontrados níveis baixos de estresse geral, emocional e social. Não foram encontradas diferenças estatisticamente significativas nos níveis estressantes e tranquilizantes entre os sexos. Conclui-se que atletas com nível maior de valores tranquilizantes e níveis estressantes baixo relataram alguns aspectos negativos, mas os aspectos psicológicos positivos se sobressaíram, o que contribui para o processo de recuperação das lesões.
\end{abstract}

PALAVRAS-CHAVE: Desempenho Esportivo. Psicologia. Recuperação. Traumatismos em Atletas.

\section{STRESS AND INJURIES IN COLLECTIVE SPORTS ATHLETES}

\begin{abstract}
The aim of this study was to analyze the levels of stress in injured athletes of collective modalities in a municipality in northwestern Paraná. The research subjects were 14 athletes of both genders, mean age 23.5 years. The instruments used were RESTQ - Sport 76 and a semi-structured interview. The Shapiro Wilk test and the Mann-Whitney U $(\mathrm{p}<0.05)$ tests were used for data analysis; content analysis was used for the open questions. The results showed that the incidence of injuries was higher in rugby athletes, with the location of injuries, in general terms, more frequent in the knees and shoulders. In relation to stress, lower levels of general, emotional and social stress were found. There were no statistically significant differences in stressing and tranquilizing levels between the genders. It can be concluded that athletes with higher levels of tranquilizers and lower levels of stress reported some negative aspects, but the positive psychological aspects have been greater, which contribute to the recovery from injury.
\end{abstract}

KEYWORDS: Athletic Injuries. Athletic Performance. Psychology. Recovery.

\section{Introdução}

O entusiasmo pelo esporte tem crescido gradualmente na sociedade contemporânea, despertando o interesse de pesquisadores em realizar estudos que investigam os aspectos físico, técnico, tático e psicológico que fazem parte deste fenômeno. A respeito dos aspectos psicológicos, pode-se citar como a principal área a Psicologia do Esporte, considerada uma área emergente (VIEIRA et al., 2010) e com importância reconhecida, principalmente, no contexto do esporte de rendimento, na busca por melhores resultados, bem como na recuperação de atletas lesionados.

A ocorrência de lesões na prática do esporte não é algo recente, pois no ano de 1981, nos Estados Unidos, cerca de setenta milhões de pessoas se lesionaram, precisando de atendimento médico ou interromperam a prática de atividade física por pelo menos um dia, e cerca de três a cinco milhões foram em decorrência dos esportes ou recreação (ANDERSEN; WILLIAMS, 1988). Junge, Dvorak e Graf-Baumann (2004) encontraram em seus estudos que nos torneios da FIFA e Jogos Olímpicos de 1998 e 2001 ocorreram 901 lesões em atletas e no estudo durante a Copa do Mundo de 2002 foram documentadas 171 lesões.
Os estudos realizados a respeito de lesão esportiva demonstram que em período de competição, os atletas que mais sofrem lesões são os que praticam esportes que exigem maior contato físico, como os esportes coletivos (RIBEIRO; COSTA, 2006; COCHEN et al., 1997). Contudo, até o presente momento não foram encontrados estudos que buscassem verificar quais as consequências psicológicas decorrentes das lesões, sobretudo o estresse.

As situações estressantes terão efeito sobre o atleta dependendo da sua percepção, afetando de forma positiva ou negativa sua recuperação. Isto porque quando o atleta interpreta os eventos estressores como estimulantes e desafiadores respondendo positivamente a eles, tende a elevar seu desempenho esportivo. Por outro lado, ao encarar a situação de forma negativa, o atleta pode sofrer um aumento de sua ansiedade, consequentemente diminuindo seu desempenho (BRANDÃO, 2000).

Algumas investigações sobre o estresse no esporte foram publicadas em periódicos nacionais (NOCE; SAMULSKI, 2002; MOREIRA et al., 2009; SANCHES; REZENDE, 2010; MOREIRA et al., 2010; NOCE et al., 2011) e no âmbito internacional (KALDA; JURIMAE, 2004; COUTTS; REABURN, 2008; FILAIRE; ROUVEIX; DUCLOS, 2009;

DOI: https://doi.org/10.25110/arqsaude.v20i1.2016.5097

${ }^{1}$ Graduado em Educação Física - Universidade Estadual de Maringá -UEM, Departamento de Educação Física - DEF. Avenida Colombo, 5790, CEP 87020900, Jardim Universitário, Maringá-PR, Brasil. marcosakamine@hotmail.com

${ }^{2}$ Mestre em Educação Física - Universidade Paranaense - Unipar. Universidade Estadual de Maringá. Programa de Pós-Graduação Associado em Educação Física UEM/UEL. Rua Helcio Siolari, 351-A, CEP 87075-800 - Jardim Everest. Maringá. Paraná. Brasil. borsatopassos@gmail.com

${ }^{3}$ Mestranda em Educação Física - Universidade Estadual de Maringá. Programa de Pós-Graduação Associado em Educação Física UEM/UEL. Av. Sophia Rasgulaeff, 885 - Jardim Alvorada. Maringá. Paraná. Brasil. gislainecontessoto@gmail.com

${ }^{4}$ Doutora em Educação Física - Universidade Estadual de Maringá -UEM, Departamento de Educação Física - DEF. Avenida Colombo, 5790, CEP 87020900, Jardim Universitário, Maringá-PR, Brasil. luarantescosta@gmail.com 
BRINK et al., 2010; NICOLAS; BANIZETTE; MILLET, 2011) porém verificou-se ausência de estudos tendo como sujeitos atletas lesionados, representando uma lacuna a ser pesquisada. Assim, este estudo teve como objetivo analisar os níveis de estresse em atletas lesionados de equipes de modalidades esportivas coletivas de uma cidade do noroeste do Paraná, participantes em competições oficiais.

\section{Material e Métodos}

Este estudo teve como método exploratório do tipo survey, no qual se utiliza um questionário e uma entrevista semiestruturada, para uma determinada população (THOMAS; NELSON, 2002). Para fins de coleta de dados o estudo faz parte do projeto institucional, submetido ao Comitê Permanente de Ética em Pesquisa (COPEP) sob o parecer $\mathrm{N}^{\circ}$ 339/2011 da Universidade Estadual de Maringá (UEM) intitulado "Estudo dos aspectos psicológicos e comportamentais relacionados ao contexto esportivo".

A população foi de aproximadamente 120 atletas, integrantes de modalidades coletivas nas categorias adultas, de equipes de um município do noroeste do Paraná. Após visita aos centros de treinamento de modalidades esportivas coletivas, de ambos os gêneros, verificou-se a existência de 14 atletas lesionados, sendo estes das seguintes modalidades: basquete $(n=4)$, rugby $(n=7)$, softbol $(n=1)$ e handebol $(n=2)$; sendo 8 do sexo masculino e 6 do sexo feminino, com média de idade $23,5( \pm 4,44)$ anos. Outras modalidades justificaram não haver atletas lesionados no momento da investigação. Os critérios de inclusão no estudo consideraram atletas lesionados de modalidades coletivas que não interromperam seus treinamentos, representando suas equipes em jogos oficiais ou amistosos.

Foi utilizado um questionário para identificar o perfil dos atletas (tempo de prática, local das lesões e tempo em que está lesionado); na análise dos aspectos psicológicos foi utilizado o questionário Restq - Sport 76 (Recovery - Stress Questionnaire for Athletes) validado para a língua portuguesa (COSTA; SAMULSKI, 2005). Este questionário contém 77 itens, sendo que o item número " 1 " não é incluso no escore final. Cada escala deste consiste em quatro itens avaliados por uma escala Likert com valores que variam de 0 a 6 pontos $(0=$ nunca, 1 = pouquíssimas vezes, $2=$ poucas vezes, $3=$ metade das vezes, $4=$ muitas vezes, $5=$ muitíssimas vezes e 6 = sempre), indicando a incidência de eventos e atividades relatadas. Os valores das escalas são calculados pelos valores médios dos respectivos itens. Cada grupo de questões é relacionado a uma das subescalas: Estresse geral (questões 22, 24, 30 e 45); Estresse Emocional (questões 5, 8, 28 e 37); Estresse Social (questões 21, 26, 39 e 48); Conflitos/ pressão (questões 12, 18, 32 e 44); Fadiga (questões 2, 16, 25 e 35); Falta de energia (questões 4, 11, 3 e 40); Queixas Somáticas (questões 7, 15, 20 e 42); Sucesso (questões 3, 17, 41 e 49); Recuperação Social (questões 6, 14, 23 e 33); Recuperação Física (questões 9, 13, 29 e 38); Bem-estar Geral (questões 10, 34, 43 e 47); Qualidade do Sono (questões 19, 27, 6 e 46); Perturbações nos Intervalos (questões 51, 58, 66 e 72); Exaustão Emocional (questões 54, 63, 68 e 76); Lesões (questões 50, 57, 64 e 73); Estar em Forma (questões 53,61,69 e 75); Aceitação Pessoal (questões 55, 60, 70 e 77); Autoeficácia (questões 52, 59, 65 e 71) e Autorregulação (questões 56, 62, 67 e 74).

Após o preenchimento dos questionários, foi realizada uma entrevista semiestruturada com os atletas lesionados, utilizando-se um gravador de voz, com objetivo de identificar os aspectos psicológicos relacionados à lesão dos atletas. A coleta de dados foi realizada antes dos treinamentos, no segundo semestre de 2011, com a autorização do treinador ou responsável pela equipe. Foi entregue uma carta convite aos atletas, explicando os objetivos da pesquisa, posteriormente, solicitando a assinatura do Termo de Consentimento Livre e Esclarecido. Para a realização da entrevista foi realizado um estudo piloto com um atleta de handebol que representou a equipe de um município do noroeste do Paraná por quatro anos, sendo que este apresentava uma lesão no joelho e havia interrompido a participação nos treinamentos.

$\mathrm{Na}$ análise dos dados quantitativos foram utilizados os procedimentos da estatística descritiva, realizados por meio do programa SPSS versão 15.0, Os quais foram apresentados em frequência relativa média e desvios padrão. Para verificação da normalidade dos dados foi utilizado o teste de Shapiro-Wilk e diante da identificação de distribuição não normal foi utilizado para comparação entre os sexos o teste não paramétrico " $U$ ” de Mann- Whitney, adotando significância de $\mathrm{p}<0,05$.

Para a análise e interpretação das questões abertas foi realizada a análise de conteúdo do tipo categorial (BARDIN, 1977). Para codificação dos atletas nos resultados e discussão e garantindo o anonimato nos depoimentos, foi utilizada a letra "A" para atleta, e o número, correspondente à ordem de transcrição. A transcrição foi realizada na íntegra, com duração de aproximadamente 2 horas para cada atleta. Para facilitar as análises e interpretação das questões abertas foram utilizados quadros com os depoimentos dos atletas, separando-os conforme as dimensões psicológicas: personalidade, história de estressores, recursos de enfrentamento, situações atléticas potencialmente estressantes, resposta ao estresse e intervenções.

\section{Resultado e Discussão}

Em relação ao tempo de prática, 78,6\% dos atletas possuem 21 ou mais meses de prática, $14,3 \%$ dos atletas têm entre 11 a 15 meses e $7,1 \%$ dos atletas entre 6 a 10 meses de prática. Os locais em que as lesões ocorreram foram variados: ombro, pescoço e tornozelo, sendo o joelho o local mais frequente $(50 \%)$. A respeito dos membros superiores, o ombro foi o local que os atletas mais se lesionaram, também com $50 \%$ de incidência. De forma geral, $35,7 \%$ dos atletas se lesionaram nos membros inferiores, $28,6 \%$ se lesionaram nos membros superiores e $35,7 \%$ dos atletas tiveram lesões nos membros inferiores e superiores. Destaque para a lesão dos membros inferiores, pois o local teve maior incidência, assim como o estudo realizado por Silva, Abdalla e Fisberg (2007) com atletas do gênero feminino, praticantes da modalidade basquete, no qual identificou a incidência de 54\% nos membros inferiores e $23 \%$ nos membros superiores.

O rugby foi o esporte que mais obteve atletas lesionados, com $50 \%$ dos atletas, seguidos do basquete com $28,6 \%$, do handebol com $14,3 \%$ e do softbol com $7,1 \%$. Observou-se que cerca de $50 \%$ dos atletas estavam lesionados há 4 semanas, $14,3 \%$ estavam entre 5 a 9 semanas, ou- 
tros $14,3 \%$ encontravam-se lesionados de 10 a 20 semanas e $21,4 \%$ dos atletas estavam a 21 semanas lesionados, sendo que dois atletas destes, estavam a 1 ano em processo de lesão, ou seja, as lesões se repetiam ao longo do ano.

Os resultados (Figura 1) demonstraram níveis baixos de "estresse geral", "emocional" e "social", indicando que, de forma geral, os atletas parecem não estar estressados, como de fato nas entrevistas, a palavra "estresse" não ocorreu em nenhum depoimento. Porém, quanto ao que se refere ao "conflito e pressão" a média foi de 3,38 , demonstrando o desconforto dos atletas em situações esportivas. Tal desconforto ou conflito pode estar relacionado com o medo do atleta em se lesionar novamente como verificado no depoimento: "Medo. Medo de machucar de novo, de fazer coisa errada, piorar..." (A9). Em um dos casos de conflito, a atleta pensa em desistir do esporte: "Então o sentimento que dá é assim de desistir, de tá na hora de parar..." (A13). Estes resultados se assemelham com o estudo (LAVOURA; MELLO; MACHADO, 2007), no qual foi utilizado um questionário com 14 questões fechadas que apontam o medo como um sentimento, e investigaram quais os medos e vergonhas de atletas do sexo feminino, indicando que as atletas tinham medo de se lesionar e não obter êxito.

Figura 1: Escores médios (zero a seis) do nível geral de eventos estressantes e tranquilizantes, em atletas com lesão de modalidades coletivas de um município do noroeste do Paraná.

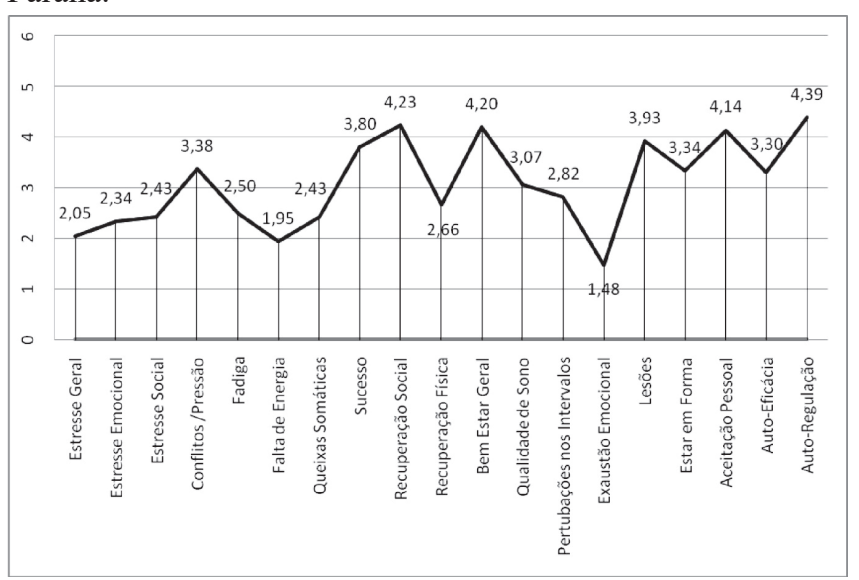

O aspecto "lesão", com a média de 3,93, demonstra que os atletas o consideram como fator estressante. A "aceitação pessoal”, obteve média de 4,14 (Figura 1) evidenciando que a reação psicológica do atleta, parece reconhecer que está lesionado e tem a consciência das consequências desta lesão(VELOSO; PIRES, 2007).

Como habilidade psicológica de controle, neste estudo a "autorregulação" atingiu média de 4,39 (Figura 1), demonstrando uma capacidade de mentalização positiva e aumentando a autoconfiança para a recuperação do atleta. A "autoconfiança" que é caracterizada por uma grande expectativa de sucesso, neste estudo apresentou média de 3,80 (Figura 1); o sucesso possibilita a concentração, desperta emoções boas, afetando as metas positivamente, aumentando as chances de não se lesionar e acelerar a recuperação(WEINBERG; GOULD, 2001).

$\mathrm{Na}$ Tabela 1 os resultados estatísticos apontaram que não houve diferença significativa entre o sexo masculino e feminino, em relação às variáveis do questionário Restq - Sport 76, corroborando estes resultados, uma análise não linear, pode-se citar o estudo realizado por Benedetti, Oliveira e Lipp (2011) que não encontraram diferença estatisticamente significativa entre os sexos no nível de estresse, em seu estudo com corredores de maratona em período de pré-competição.

Tabela 1: Comparação dos níveis estressantes e tranquilizantes em atletas lesionados, entre os sexos masculino e feminino de equipes de uma cidade do noroeste do Paraná.

\begin{tabular}{|c|c|c|c|}
\hline Variáveis & $\begin{array}{c}\text { Masculino } \\
(n=8) \\
M d(Q 1-Q 3)\end{array}$ & $\begin{array}{c}\text { Feminino } \\
(n=6) \\
M d(Q 1-Q 3)\end{array}$ & $p$ \\
\hline $\begin{array}{l}\text { Estresse } \\
\text { Geral }\end{array}$ & $1,50(1,12-2,25)$ & $1,37(1,18-4,37)$ & 0,89 \\
\hline $\begin{array}{l}\text { Estresse } \\
\text { Emocional }\end{array}$ & $1,75(1,31-3,31)$ & $2,25(1,81-3,31)$ & 0,51 \\
\hline $\begin{array}{l}\text { Estresse So- } \\
\text { cial }\end{array}$ & $1,75(1,06-4,25)$ & $2,37(0,68-4,12)$ & 0,84 \\
\hline $\begin{array}{l}\text { Conflito/ } \\
\text { Pressã̃o }\end{array}$ & $3,12(2,12-4,18)$ & $3,62(2,93-4,31)$ & 0,36 \\
\hline Fadiga & $2,50(1,68-3,81)$ & $2,50(0$, & 0,74 \\
\hline $\begin{array}{l}\text { Falta de } \\
\text { Energia }\end{array}$ & $1,87(1,00-2,56)$ & $2,00(0,75-3,00)$ & 1,00 \\
\hline $\begin{array}{l}\text { Queixas } \\
\text { Somáticas }\end{array}$ & $2,50(2,25-3,50)$ & $2,25(0,62-3,62)$ & 0,47 \\
\hline Sucesso & $4,12(3,56-4,50)$ & $3,37(2$, & 0,19 \\
\hline $\begin{array}{l}\text { Recupera- } \\
\text { ção Social }\end{array}$ & $4,75(3,00-5,50)$ & $4,37(2,37-5,06)$ & 0,47 \\
\hline $\begin{array}{l}\text { Recupera- } \\
\text { ção Física }\end{array}$ & $6-3,18)$ & $2,75(1,62-4,37)$ & 0,60 \\
\hline $\begin{array}{l}\text { Bem Estar } \\
\text { Geral }\end{array}$ & $4,75(3,37-5,25)$ & $4,12(2,62-5,00)$ & 0,43 \\
\hline $\begin{array}{l}\text { Qualidade } \\
\text { do Sono }\end{array}$ & $2,50(2,25-3,37)$ & $2,62(2,25-3,00)$ & 0,89 \\
\hline $\begin{array}{l}\text { Perturba- } \\
\text { ções nos } \\
\text { Intervalos }\end{array}$ & $2,62(2,06-4,06)$ & $3-4,00)$ & 0,65 \\
\hline $\begin{array}{l}\text { Exaustão } \\
\text { Emocional }\end{array}$ & $1,37(1,25-1,68)$ & $1,50(0,00-3,06)$ & 1,00 \\
\hline Lesão & $12(3,50-4,50)$ & $3,75(2,68-5,06)$ & 0,69 \\
\hline $\begin{array}{l}\text { Estar em } \\
\text { Forma }\end{array}$ & $3,75(2,62-4,37)$ & $2,87(1,37-4,37)$ & 0,39 \\
\hline $\begin{array}{l}\text { Aceitação } \\
\text { Pessoal }\end{array}$ & $4,25(3,75-5,00)$ & $3,87(3,43-4,18)$ & 0,13 \\
\hline Autoeficácia & $3,50(2,81-4,25)$ & $3,37(1,62-4,43)$ & 0,84 \\
\hline $\begin{array}{l}\text { Autorregı } \\
\text { lação }\end{array}$ & $5,25(4,31-5,75)$ & $4,00(2,12-5,12)$ & 0,08 \\
\hline
\end{tabular}

Md: mediana; (Q1-Q3): intervalo interquartílico; p: índice de significância $(p<0,05)$.

Conforme a análise das entrevistas observou-se no processo da lesão dos atletas, a história de estressores, que se tratam de lesões anteriores que não foram tratadas corretamente (ANDERSEN; WILLIAMS, 1988) como é possí- 
vel observar no seguinte depoimento: “[...] ele já era meio machucado, dos treinos de handebol [...]" (A8), ou seja, o atleta já estava com uma lesão no joelho decorrente da prática do handebol e por causa disso, a lesão surgiu novamente em outra modalidade, o rugby. Na história de estressores, há também os aborrecimentos diários da vida esportiva, causadas pelo excesso de treinamento, pouco tempo de descanso, como na fala a seguir: "Falta de descanso, falta de descanso... acho que... pode te atrapalhado um pouco, porque eu tive muito pouco tempo de descanso por causa da faculdade e outras coisas (A12).

Pode-se observar no depoimento que o excesso de treinamento ou outras atividades que não são esportivas, indica que o atleta está fadigado, causando um aborrecimento em estar lesionado e não tem tempo para recuperar a lesão, pelo excesso de treino e estudos. Ainda sobre o argumento do atleta, este não aparenta ter recursos de enfrentamento, como os recursos de controle de estresse, o apoio dos atletas, amigos ou familiares, portanto um enfrentamento ainda mais complexo. Já com outro atleta lesionado, percebe-se o apoio da família:

[...] os fisioterapeutas daqui tinham falado que eu ia ter que operar né mano, então, eu mesmo pus na minha cabeça eu tinha que operar né... os meus pais também, falando tal, isso aí eu acho que [...] pra mim eu acho né [...] (A14).

Outros recursos de enfrentamento foram encontrados nos depoimentos: “[...] como eu digo pra você, eu vivi isso daí, então entra droga, entra anabolizante, entra essas parada entra não sei o que, um monte de coisa a mais" (A7). $\mathrm{O}$ atleta utilizou drogas lícitas para enfrentar os problemas do esporte de alto rendimento, podendo prejudicar o processo da lesão e aumentando as respostas ao estresse.

Após a análise das entrevistas, 64\% dos atletas discorreram que suas lesões ocorreram em treinamento e $36 \%$ disseram que foi em campeonato ou amistoso. Os dados vão ao encontro de um estudo (ARENA; CARAZZATO, 2007) no qual também foi identificado que mais da metade das lesões ocorriam quando os atletas estavam em período de treinamento. Queixas quanto o excesso de treinamento foram relatadas pelos atletas como, por exemplo:

\footnotetext{
"Mas algum tempo eu venho sentindo desconforto no ombro, sinto desconforto no joelho, no tornozelo... então consequentemente é... a lesão acaba aparecendo, porque você esta fadigada, você treina todos os dias... nós treinamos todos os dias duas horas por dias, de segunda a sábado e quando tem feriado a gente treina aos domingos também (A13).
}

Cohen et al. (1997), apontaram que o excesso de jogos, viagens, competições importantes, influenciam no risco de lesão por ser fatores que afetam o estado psicológico do atleta. Paralelamente o excesso de treinamento também é um agravante psicológico, pois está em período pré-competitivo e com o excesso de carga de treinamentos, podendo causar e agravar as lesões.

Estes aspectos demonstram situações potencialmente estressantes da vida de um atleta; diante disso, outro atleta se queixou de dores no ombro, quando voltou a realizar os treinos físicos, como em sua fala: "É, inclusive hoje eu não corri, porque, eu corri ontem e senti dor" (A7). Segundo Hillman(2002) os atletas que realizam os treinamentos no período de recuperação de uma lesão, têm dores nos membros importantes para realização do esporte, podendo até modificar a maneira de correr, como no caso do atleta, além disso, pode estar propenso a se lesionar em outro local devido à mudança no estilo de corrida, pois, o entrevistado complementa: "Tem que sustentar o ombro na corrida. E aí na verdade não doeu a lesão, doeu a... os outros grupos musculares tentando trabalhar" (A7). Contudo, a modificação de sua marcha pode sobrecarregar os músculos auxiliares que sustentam o ombro e possibilitar outra lesão muscular. Também foi identificado o fator estressante situacional competitivo nas entrevistas, como se observou no depoimento:

"[...] você tenta dar o máximo e não conseguir, essa é a principal dificuldade, não é tanto a dor, é a dificuldade de dar o máximo". "[...] mesmo o que me prejudica mais é o fato de saber que a competição esta próxima e você não conseguir realmente treinar o com tudo né [...]" conseguir dar tudo o que você poderia dar, se tivesse sem nenhuma lesão" (A6).

No momento em que o atleta relata que é necessário render o máximo e a pressão da competição é uma situação estressante presente no cotidiano esportivo, este processo acaba influenciando na resposta ao estresse e por fim, pode propiciar o acontecimento de novas lesões. No mesmo sentido, o esporte competitivo é um episódio causador de estresse, além de haver a incessante busca pelo desempenho máximo, certas vezes estará em confronto com um adversário que busca superar ou dificultar sua ação (MACHADO, 1997). Além disso, outro atleta, em seu depoimento, revelou que seu esporte necessita de constante confronto direto (contato) com um adversário, apontando medo e preocupação:

"Com certeza, porque eu tenho que cuidar mais, principalmente no rugby, usa bastante o ombro, então tive que tomar muito mais cuidado com o ombro, às vezes evitando entrar em jogadas, pra proteger o ombro" (A5).

Dessa maneira, o medo é uma resposta ao estresse, caracterizada pelo sentimento de nervosismo, tensão e opressão, atendendo como resposta ou alerta, para situações que podem ser ameaçadoras ou perigosas. No contexto esportivo o medo é um desajuste psíquico que acompanham outros desajustes emocionais, causados pelo estresse, ansiedade e elevados e intensos estados emocionais (LAVOURA; MELLO; MACHADO, 2007). Outro exemplo de medo no meio esportivo e que contempla neste estudo, é do medo de uma nova lesão, como neste depoimento:

"Medo. Medo de machucar de novo, de fazer coisa errada, piorar" [...] (A9), e quando o atleta foi questionado sobre o rendimento, argumentou da seguinte forma: "[...] por causa do medo até às vezes eu não vou com tanto entusiasmo" (A9), este atleta tem o medo de se lesionar novamente.

O medo provoca a insegurança no movimento, prejudicando as habilidades motoras e desempenho do atleta, acarretando a diminuição do rendimento e contribuindo para 
o acontecimento de novas lesões (LAVOURA; MELLO; MACHADO, 2007).

Outro fator que influencia no desempenho esportivo é a ansiedade-traço, que é uma característica que pode causar variações antecipadas no desempenho (DE ROSE; VASCONCELLOS, 1997) e pôde ser detectado no depoimento de um atleta:

"Ah... talvez essa frustração né, tipo a ansiedade de querer voltar, e às vezes, como eu falei antigamente, eu voltava, eu era muito ansioso, eu voltava sem me recuperar totalmente..." (A11).

O depoimento mostra a frustração do atleta e a ansiedade de voltar à prática esportiva, mesmo estando lesionado, e com isso a resposta ao estresse, causando uma mudança no nível de atenção do atleta, afetando o rendimento e podendo acarretar em uma nova lesão.

Também podemos notar no depoimento do atleta (A11) a ansiedade-traço como componente permanente da personalidade (PUJALS; VIEIRA, 2002). Andersen e Williams (1998) também enquadram a ansiedade-traço na personalidade, e isso afeta na resposta ao estresse e pode ocasionar a lesão, devido à diminuição da atenção, pois a ativação estreita o campo de visão, afetando o controle motor (WEINBERG; GOULD, 2001).

Outro fator da personalidade que influencia na resposta ao estresse é a motivação, conforme o seguinte depoimento: “[...] isso dá mais motivação né, porque muitos... igual à cirurgia que eu fiz... é... a cada dez pacientes que faz, um volta a jogar" (A2). Portanto, o atleta é motivado, pois tem a necessidade de superar a lesão e com isso o atleta reage com a intenção de suplantar a lesão (LOBO, 1973).

Um recurso que tende a diminuir as respostas ao estresse são as intervenções psicológicas, como as técnicas de relaxamento, treinamento de confiança, ensaio positivo (ANDERSEN; WILLIAMS, 1988), evidenciado no depoimento do atleta: "[...] tô fazendo de tudo num... num piora não. Eu quero voltar a jogar logo" (A2). Além disso, pode-se observar outras intervenções psicológicas que os atletas utilizam, como por exemplo: o mesmo atleta, relata a sua superação:

"[...] mais de superação mesmo, porque como a cirurgia é muito grave, e a expectativa de retorno do atleta é quase zero, então eu quero mostra que eu posso voltar... mesmo com toda dificuldade, fazendo o tratamento certinho eu posso voltar a ter o rendimento de um atleta normal. Então assim... é mais pela superação mesmo" (A2).

Diante das entrevistas e do questionário sobre níveis estressantes e tranquilizantes para atletas (Figura 1), aponta outros recursos de enfrentamento relacionados com a motivação e superação, e mostra a forma que os atletas utilizam para a recuperação da lesão, é a autorregulação $(4,39)$, recuperação social $(4,23)$, bem-estar geral $(4,20)$ e aceitação pessoal $(4,14)$.

Uma definição geral para motivação, segundo Sage apud Weinberg e Gould(2001), é a direção e a intensidade de esforços, no caso dos atletas, está focando os esforços a recuperar a lesão para voltar o quanto antes para o esporte como a seguinte fala: "Eu acredito que não né... para não piorar. Eu quero voltar a jogar logo" (A2).
A aceitação pessoal pode estar relacionada com os recursos de enfrentamento diante as situações estressantes (ANDERSEN; WILLIAMS, 1988), ao invés de sentir inútil, o atleta sente que é importante para a equipe como na fala:

“[...] porque eu sou o único canhoto da equipe do... na armação... Então assim... isso acaba... um pouco... deixando um pouco a desejar, por mais que tenha um atleta, que ele tá com um rendimento muito bom na... Na meia alí, só que... é sempre bom ter um canhoto, então assim, eu também quero voltar pra ta ajudando na equipe" (A2).

Neste depoimento pode ser observado um subjetivo apoio social, o que também foi verificado nos dados quantitativos da "recuperação social" com a média 4,23 (Figura 1), que segundo Weinberg e Gould (2001) o apoio social advêm do apoio emocional de amigos, familiares e técnicos.

Por fim, outro dado de relevância foi o "bem estar geral" com a média 4,20 (Figura 1), que parece ser o oposto dos aborrecimentos diários proposto por Andersen e Williams (1988), que justifica os aborrecimentos diários como história de estressores, que exerce influência na ocorrência de lesão, ou seja, os atletas apresentam bem-estar e com isso uma forma para recuperação das lessões.

\section{Conclusões}

Objetivou-se analisar os níveis de estresse em atletas lesionados de equipes de modalidades esportivas coletivas de uma cidade do noroeste do Paraná. Conclui-se que atletas com nível maior de valores tranquilizantes e níveis estressantes baixo relataram o desconforto em situações de pressão esportiva, medo de se lesionar, ansiedade, preocupação com o retorno às competições, mas os aspectos psicológicos positivos se sobressaíram em relação aos negativos, o que contribui para o processo de recuperação das lesões.

A limitação deste estudo foi não ter acesso aos atletas lesionados que estavam afastados da equipe a qual pertenciam antes da lesão. Para futuros estudos sugere-se incluir um instrumento que verifique as estratégias de coping, além do estresse e a entrevista semiestruturada, a fim de contribuir para o processo de treinamento esportivo na busca pelo melhor desempenho, como também para a qualidade de vida dos atletas.

Atentamos para a necessidade de acompanhamento dos atletas lesionados por profissionais especializados, dentre eles professores de educação física, médicos, psicólogos do esporte e treinadores, pois esses profissionais poderiam auxiliar na prevenção e recuperação das lesões, por meio de treinos adequados, instruções médica e psicológica.

\section{Referências}

ANDERSEN, M. B.; WILLIAMS, J. M. A model of stress and athletic injury: prediction and prevention. J Sport Exerc Psychol, v. 10, n. 3, p. 294-306, 1988.

ARENA, S. S.; CARAZZATO, J. G. A relação entre o acompanhamento médico e a incidência de lesões esportivas em atletas jovens de São Paulo. Rev Brasi Med Esporte, São Paulo, v. 13, n. 4, p. 217-221, 2007. 
BARDIN, L. Análise de conteúdo. Lisboa: Edições 70, 1977.

BENEDETTI, E.; OLIVEIRA, R. L.; LIPP, M. E. N. Nível de stress em corredores de maratona amadores em período de pré-competição. Rev. bras. Ci. e Mov. Brasília, v. 3, n. 19, p. 5-13, 2011.

BRANDÃO, M. R. F. Fatores de "stress" em jogadores de futebol profissional. 2000. Tese (Doutorado em Ciências do Esporte) - Escola de Educação Física da Universidade de Campinas, Campinas, 2000.

BRINK, M. S. et al. Monitoring stress and recovery: new insights for the prevention of injuries and illnesses in elite youth soccer players. Br J Sports Med. v. 44, p. 809-815, 2010.

COHEN, M. et al. Lesões ortopédicas no futebol. Rev. bras. ortop. São Paulo, v. 32, n. 12, p. 940-944, 1997.

COSTA, L. O. P.; SAMULSKI, D. M. Processo de validação do questionário de estresse e recuperação para atletas (RESTQ-Sport) na Língua Portuguesa. Rev. bras. Ci. e Mov. Brasília, v. 13, n. 1, p. 79-86, 2005.

COUTTS, A. J.; REABURN, P. Monitoring changes in rugby league players' perceived stress and recovery during intensified training. Percept Mot Skills, v. 106, p. 904-916, 2008.

DE ROSE JÚNIOR, D.; VASCONCELLOS, E. G. Ansiedade-traço competitiva e atletismo: um estudo com atletas infanto-juvenil. Rev. paul. educ. fís. São Paulo, v. 11, n. 2, 148-154, 1997.

FILAIRE, E.; ROUVEIX, M.; DUCLOS, M. Training and 24hr urinary catecholamine excretion. Int J Sports Med. v. 30, p. 33-39, 2009.

HILLMAN, S. Avaliação, prevenção e tratamento imediato das lesões esportivas. São Paulo: Manole, 2002.

JUNGE, A.; DVORAK, J.; GRAF-BAUMANN, T. Football injuries during FIFA tournaments and the Olympic games, 1998-2001: development and implementation of an injuryreporting system. Am. J Sports Med. v. 32, n. 1, p. 80-89, 2004.

KALDA, J.; JURIMAE, T.; JURIMAE, J. Relationships between recovery-stress state and performance in sprinters and jumpers. Percept Mot Skills, v. 99, p. 12-16, 2004.

LAVOURA, T. N.; MELLO, C. C. C.; MACHADO, A. A. Estados emocionais na prática esportiva: relações entre medo e vergonha no contexto esportivo. Rev. bras. Ci. e Mov. Brasília, v. 15, n. 3, p. 77-84, 2007.

LOBO, R. J. H. Psicologia dos esportes. São Paulo: Atlas, 1973.
MACHADO, A. A. Psicologia do esporte: temas emergentes I. Jundiaí: Ápice, 1997.

MOREIRA, A. et al. Esforço percebido, estresse e inflamação do trato respiratório superior em atletas de elite de canoagem. Rev. bras. educ. fís. esporte, São Paulo, v. 23, n. 4, p. 355-363, out./dez. 2009.

MOREIRA, A. et al. Percepção de esforço da sessão e a tolerância ao estresse em jovens atletas de voleibol e basquetebol. Rev Bras Cineantropom Desempenho Hum. v. 5 , n. 12 , p. $345-351,2010$.

NICOLAS, M.; BANIZETTE, M.; MILLET, G.Y. Stress and recovery states after a $24 \mathrm{~h}$ ultra-marathon race: a onemonth follow-up study. Psychology of Sport and Exercise, v. 12, p. 368-374, 2011.

NOCE, F. et al. Análise dos sintomas de overtraining durante os períodos de treinamento e recuperação: estudo de caso de uma equipe feminina da superliga de voleibol 2003/2004. Rev Bra Med Esporte, v. 17, n. 6, nov./dez. 2011 .

NOCE, F.; SAMULSKI, D. M. Análise do estresse psíquico em atacantes no voleibol de alto nível. Rev. paul. educ. fís. v. 16, n. 2, p. 113-129, jul./dez. 2002.

PUJALS, C.; VIEIRA, L.F. Análise dos fatores psicológicos que interferem no comportamento dos atletas de futebol de campo. Rev. Educ. Fís/UEM, Maringá, v. 13, n. 1, p. 8997, set. 2002.

RIBEIRO, N. R.; COSTA, L. O. P. Análise epidemiológica de lesões no futebol de salão durante o XV Campeonato Brasileiro de Seleções Sub 20. Rev Bras Med Esporte, v. 12, n. 1, jan./fev. 2006.

SANCHES, A. B.; REZENDE, A. L. G. Avaliação da percepção das situações de estresse de jogadores de futebol em função da idade. Rev. bras. Ci. e Mov. v. 3, n. 18, p. 43-50, 2010.

SEGATO, L. et al. Estresse psicológico de velejadores de alto nível esportivo em competição. Revista Motricidade, v. 6, n. 3 , p. 53-62, 2010.

SILVA, A. S.; ABDALLA, R. J.; FISBERG, M. Incidência de lesões musculoesqueléticas em atletas de elite do basquetebol feminino. Acta ortoped bras. v. 15, n. 1, p. 43-46, 2007.

THOMAS JUNIOR, NELSON J. K. Métodos de pesquisa em atividade física. 3. ed. Porto Alegre: Artmed, 2002.

VELOSO, S.; PIRES, A. P. A psicologia das lesões desportivas: importância da intervenção psicológica. Revista Portuguesa de Fisioterapia no Desporto, v. 1, n. 2, p. 38-47, jul. 2007.

VIEIRA, L. F. et al. Psicologia do esporte: uma área 
emergente da psicologia. Psicol. stud. v. 15, n. 2, p. 391399, abr./jun. 2010.

WEINBERG RS, GOULD D. Fundamentos da psicologia do esporte e do exercício. 2. ed. Porto Alegre: Artmed, 2001.

Recebido: 02/06/2015

Aceito: $30 / 11 / 2015$ 